\title{
Epidemiological Studies on Ovine Lungworm Species in Northern Ethiopia
}

\section{Andualem Yimer* and Abebe Desie}

School of Veterinary Medicine, Wollo University, Dessie, Ethiopia

\begin{abstract}
A cross sectional study was conducted from November, 2015 to April, 2016 to determine the prevalence, associated epidemiological factors and identifying the species of ovine respiratory helminthes circulating in and around Wogera district. Modified Baermann technique was conducted to detect first stage larvae (L1) from 386 randomly sampled sheep kept under extensive and semi intensive management systems. Out of the total 386 faecal samples examined 180 were found to harboring one or more lungworm parasites with an overall prevalence of $46.6 \%$ (180/386). Dictyocaulus filarial (D. filaria) was the dominant lungworm species with prevalence of $18.9 \%$, followed by Mulliries capillaries ( $M$. capillaries) $14.2 \%$, Protostrongylus rufescens ( $P$. rufescens) $2.3 \%$ and Mixed infection with $D$. filarial and $M$. capillaries species $(11.1 \%)$. In this study, animals with poor body condition $(23.1 \%)$ were highly infected with significant difference $(\mathrm{P}<0.05)$ than medium $(14.8 \%)$ and good body conditions $(8.8 \%)$ There was statistical significant difference in susceptibility between different age groups $(P<0.05)$, the young $(25.1 \%)$ being more affected than adult $(22.5 \%)$ animals. Significant differences $(P<0.05)$ were found among areas of different altitude with an infection rate of $29 \%$ and $17.6 \%$ at higher and medium altitude areas respectively. Sheep kept under extensive management system and semi intensive management system also showed statistically significant variation $(\mathrm{P}<0.05)$ in infection rate with different lung worm species. The overall results obtained during this investigation showed that $D$. filaria is the most common lungworm species in its not only high prevalence rate, but also high degree of association with occurrence of clinical respiratory signs. The result of this study indicated that lungworms in sheep are common parasites which induce heavy economic loss that needs greater attention due to its impact on sheep production of the study area.
\end{abstract}

Keywords: Epidemiological factors; Ethiopia; Lungworm; Prevalence; Wogera district

\section{Introduction}

Ethiopia possesses over 25 million sheep and 21 million goats [1], parallel to its diverse ecology, production systems and ethnic communities. The CSA of Ethiopia estimated [1] that farmers in Amhara region, north eastern Ethiopia, had a total of 6.4 million sheep which are representing $25 \%$ sheep population of the country. According to $\mathrm{FAO}$ [2], $25 \%$ of the total annual meat production of the country comes from sheep. At the national level, sheep and goat account for about $90 \%$ of the live animal/meat and $92 \%$ of skin and hide export trade value of the country [2]. Small ruminants in Ethiopia are well adapted to local climatic and nutritional conditions and contribute greatly to the national economy however; poor animal management coupled with infectious and parasitic disease had reduced productivity of small ruminants [3].

Helminth parasites are among the causes of substantial productivity losses in ovine production of the country [4]. Respiratory diseases resulting from helminthes parasites are of a great economic concern in sheep production in the highlands of Ethiopia where sheep are important livestock units $[5,6]$. The three respiratory parasites that cause a significant damage in small ruminant production are $D$. filaria, $P$. rufescent and $M$. capillarius. From those lungworms particularly $D$. filaria can suppress the immunity of the respiratory tract and causes death, poor weight gain or loss of body weight as well as greatly affects the potential productivity of sheep in the areas where it is prevalent [7].

Few studies have been conducted in some areas of Ethiopia indicated high prevalence of lungworm infection in sheep population and its economic importance of the infection in certain areas of the country. Prevention and control of these parasites are therefore, essential for releasing the potential of sheep production in the country. However, in order to lay down lungworm control strategy at local and regional level, detailed investigation of current epidemiological situation and infection rate of lungworm infection in sheep population in the present study area is necessary, where sheep are important assets to the local farmers. Therefore, the objectives of this study were, to determine the prevalence of lungworm infection in sheep, identifying the major lungworm species circulating in and around Wogera district and epidemiological factors affecting the prevalence.

\section{Materials and Methods}

\section{Study area}

The study was conducted in Wogera district starting from November 2015 to April 2016. Wogera is one of the districts of North Gondar Administrative Zone, in Amhara regional state, located at 782 $\mathrm{km}$ northern of the capital city, Addis Ababa, in between $37.36^{\circ} \mathrm{E}$ and $12.46^{\circ} \mathrm{N}$ longitude and at an altitude of 2900 m.a.s.l in the northern highlands of Ethiopia. The rainfall pattern of the district is bimodal, with a short rainy season from March to May, followed by a long rainy season from June to September. It has an average annual rainfall of 700 $\mathrm{mm}$ and the mean annual temperature is $12.7^{\circ} \mathrm{C}$ [8].

\section{Study population}

Indigenous sheep reared under small holder farming system of

*Corresponding author: Andualem Yimer, Assistant Professor, School of Veterinary Medicine, Wollo University, PO Box 977, Dessie, Ethiopia, Tel: 0338519009; E-mail: anduyimer007@gmail.com

Received September 15, 2016; Accepted September 30, 2016; Published October 05, 2016

Citation: Yimer A, Desie A (2016) Epidemiological Studies on Ovine Lungworm Species in Northern Ethiopia. J Vet Sci Technol 7: 387. doi: 10.4172/2157 7579.1000388

Copyright: (ㅇ 2016 Yimer A, et al. This is an open-access article distributed under the terms of the Creative Commons Attribution License, which permits unrestricted use, distribution, and reproduction in any medium, provided the original author and source are credited. 
extensive and semi intensive management system in the study area from two agro ecological areas (highland and midland) with different sex, age, and body condition score (poor, medium and good) [9] were used during the study period. The age of the animals was estimated by stage of dentition [10], based on these animals were categorized into young age groups ( $<1$ years) and adult aged groups ( $>3$ years). Sheep those have clinical respiratory sign as shown by coughing and nasal discharge were examined and recorded before sample taking and apparently healthy animals were also isolated and recorded before sampling. The risk factors were assessed for the presence of possible significant association with presence of lung worm infection.

\section{Study design and sampling method}

A cross-sectional study to determine the prevalence of lungworm infestation and stratified random sampling techniques were used to collect the data. Out of 25 of peasant association of Wogera district, 6 peasant association of the district were selected by considering the difference in altitude. From the selected peasant associations, households were randomly selected. Sheep from each selected household of peasant association was examined with equal sample size from each peasant association.

\section{Sample size determination}

Simple random sampling strategy was followed to collect feces from the individual animals and a total of 386 fecal samples were collected and examined for lung worm nematodes, from purposively selected 6 peasant association of the district. To calculate the total size, the sample size was decided based on the formula described by Thrusfield [11]. The previous prevalence report of lung worm infection in sheep in Wogera district was reported to be $67.69 \%$ [12]. Therefore, an expected prevalence of $67.69 \%$ will be taken to estimate the sample size. Taking $95 \%$ confidence level, $5 \%$ precision and 336 sheep was need to establish the prevalence. However, 50 sheep were added in the study to increase the level of precision and randomness, and 386 sheep was sampled.

\section{Sample collection and parasitological examination}

Fecal samples were collected directly from the rectum of each sampled animal with strict sanitation and placed in air and water tight sample vial, while collecting fecal samples, necessary parameters (date of sampling, sex, age, body condition, respiratory symptoms, altitude and management system) were properly recorded, and brought to Gondar University Veterinary Parasitology Laboratory. When samples were reached in the laboratory they were immediately stored in the refrigerator $\left(4^{\circ} \mathrm{C}\right)$ until they were processed.

For coproscopic examination of the fecal samples, a modified Baermann technique as described by Charles and Robinson [13] was employed to identify first stage larvae (L1) of lung worms. Briefly, 3 $\mathrm{g}$ of fecal sample was enclosed in gauze, fixed on to string rod and submerges in clean beaker filled with tape water and left for $24 \mathrm{hrs}$. The larvae in the feces migrate to the gauze and settle at the bottom of the beaker. After siphoning of the supernatant, the sediment was examined under stereo microscope, when L1 larvae of lung worms were observed under the microscope, a drop of $1 \%$ iodine solution was added to the sediment to immobilize the larvae for species identification [14]. Finally, first stage larvae (L1) were morphologically differentiated and identified [15].

\section{Data analysis}

Data collected from the study were entered to MS Excel sheet and analyzed by using SSPS version 20 software. Descriptive statistics was used to determine the prevalence of lung worm nematodes and Pearson chi square test was used to assess the degree of association between each risk factor such as sex, age, body condition, altitude, management system and respiratory syndromes with lung worm infection. In all analyses confidence level was held at $95 \%$ and P-value less than 0.05 was considered as significant.

\section{Results and Discussion}

Of the total 386 sheep examined over the study period, 180 were positive for lung worm infections and the study indicated an overall lungworm infection prevalence of $46.6 \%$ in Wogera district, northern Ethiopia. First stage larvae of D. filaria (18.9\%), M. capillaris (14.2\%), and $P$. rufescens $(2.3 \%)$ were observed as single and mixed infections. Mixed infections were formed and observed between $D$. filaria and $M$. capillaries in $11.1 \%$ of sheep. This finding almost coincides with previous reports of overall prevalence rate of lung worm infection $48 \%$ in Addis Ababa by Mezgebu [16], 43.33\% in Dessie zuria by Basaznew et al. [17] and $42 \%$ in North Gondar Zone by Yitagel et al. [18]. However, it was higher than reports of Muluken [19] in and around Bahir Dar, Kassa and Abdu [20] in Bahir Dar and Gebreyohannes et al. [21] in Mekedella Woreda, south east Ethiopia who reported prevalence of 18.16\%, 20.2\% and $28.6 \%$ respectively. With regard to the species of lungworms, it was observed that $D$. filarial was the predominant lung worm species in the study area followed by M. capillaries and P. rufescens in sampled sheep. This finding is more or less agrees with the previous findings of Nibret et al. [12] in Wogera district, northern Ethiopia, Tefera and Mekuria [22] in Debre Birhan Town who reported D. filarial is the dominant species to cause lung worm infection in sheep. However, in contrast to the present finding higher proportion of $M$. capillaries species was identified by Yitagel et al. [18] in North Gondar zone and Asaye and Alemneh [23] in and Around Bahir Dar City. The possible explanation for such variation in the prevalence of lung worm infection in different study areas could be attributed variation in agro-ecology of the study areas which favor or disfavor the survival of parasites larvae in general and/or the presence or absence of snail intermediate host in case of $P$. rufescens and M. capillaris in the study sites. Moreover, according to Bradford [24], the occurrence of lungworms is associated with time of sampling, methods followed to detect the parasitic larvae, level of immunity of sampled animals, management practice of the animal and expansion of veterinary services (Table 1).

In relation to the prevalence of lung worm infection in different age groups, $25.1 \%$ of young examined sheep were infected with different species of lung worm while, $22.5 \%$ of adult sheep were found infected with different species of lungworm. There is statistically significant difference in age susceptibility, the young age group being more affected by D. filaria (10.4\%). This is in agreement with reports of Feseha and Gebrenegus [25], Teffera et al. [26] and Yohannes [27] in different part of Ethiopia who reported young animals are significantly more affected by different lung worm species than adult sheep. In contrast, this finding Besaznew et al. [17] in Dessie Zuria District, northeastern Ethiopia, reported higher prevalence of lung worm infection in adult animals. This variation in prevalence among different age groups might be due to the fact that there is development of acquired immunity in the adults due to previous exposure to the parasite and sheep that have recovered from previous infection have better protection (immunity against) re-infection [15].

In the present finding both sexes showed insignificant difference in susceptibility to infection with lungworms, even though the prevalence in female (32.4\%) relatively higher than male (14.2\%). This 
Citation: Yimer A, Desie A (2016) Epidemiological Studies on Ovine Lungworm Species in Northern Ethiopia. J Vet Sci Technol 7: 387. doi: 10.4172/2157-7579.1000388

Page 3 of 4

\begin{tabular}{|c|c|c|c|c|c|c|c|c|}
\hline \multirow{2}{*}{ Factors } & \multirow{2}{*}{$\begin{array}{c}\text { Animals } \\
\text { examined (\%) }\end{array}$} & \multicolumn{5}{|c|}{ Prevalence of lungworm species (\%) } & \multirow{2}{*}{$x^{2}$} & \multirow{2}{*}{ P-value } \\
\hline & & D. filaria & M. capillaries & P. rufescens & Mixed infection & Total positive & & \\
\hline Age & & & & & & & 15 & 0.00 \\
\hline Young & $170(44)$ & $40(10.4)$ & $27(7)$ & $4(1)$ & $26(6.7)$ & $97(25.1)$ & & \\
\hline Adult & $216(56)$ & $33(8.5)$ & $28(7.3)$ & $5(1.3)$ & $17(4.4)$ & $83(22.5)$ & & \\
\hline Sex & & & & & & & 4.6 & 0.33 \\
\hline Male & $124(32.1)$ & $27(7)$ & $12(3.1)$ & $4(1)$ & $12(3.1)$ & $55(14.2)$ & & \\
\hline Female & $262(67.9)$ & $46(11.9)$ & $43(11.1)$ & $5(1.3)$ & $31(8)$ & $125(32.4)$ & & \\
\hline Body Condition & & & & & & & 48 & 0.00 \\
\hline Poor & $127(32.9)$ & $37(9.6)$ & $23(6)$ & $4(1)$ & $25(6.5)$ & $89(23.1)$ & & \\
\hline Medium & $147(38.1)$ & $20(5.2)$ & $21(5.4)$ & $4(1)$ & $12(3.1)$ & $57(14.8)$ & & \\
\hline Good & $112(29.0)$ & $16(4.1)$ & $11(2.8)$ & $1(0.3)$ & $6(1.6)$ & $34(8.8)$ & & \\
\hline \multicolumn{9}{|c|}{ Management System } \\
\hline Extensive & $340(88.1)$ & $65(16.8)$ & $51(13.2)$ & $9(2.3)$ & $41(10.6)$ & $166(43)$ & 7.1 & 0.01 \\
\hline Semi intensive & $46(11.9)$ & $8(2.1)$ & $4(1)$ & - & $2(0.5)$ & $14(3.6)$ & & \\
\hline Location & & & & & & & 6.5 & 0.04 \\
\hline Highland & $206(53.4)$ & $43(11.1)$ & $34(8.8)$ & $6(1.6)$ & $29(7.5)$ & $112(29)$ & & \\
\hline Midland & $180(46.6)$ & $30(7.7)$ & $21(5.4)$ & $3(0.8)$ & $14(3.6)$ & $68(17.6)$ & & \\
\hline Total & $386(100)$ & $73(18.9)$ & $55(14.2)$ & $9(2.3)$ & $43(11.1)$ & $180(46.6)$ & & \\
\hline
\end{tabular}

Table 1: Lungworm infestation in sheep by age, sex, body condition, management system and altitudes taken as risk factors for infestation.

finding was in agreement with studies reported by Desta et al. [28] in Ambo District, Eyob and Matios [29,30] in Asella province and Gebreyohannes et al. [21] in Mekedella district, South Wollo, Ethiopia. This higher prevalence rate of lung worm infection in female animal could be due to the fact that the resistance to infection is abolished at the time of parturition and during early lactation in female animals. However, this result contradicts with the findings of Nibret et al. [12] in Wogera District; Weldesenebet and Mohamed [30] in Jimma, who reporter higher prevalence of lung worm infection in males than female animals. These variations may be due to the improper distribution of sample selection between the two sexes [31], and most of the sampled sheep are not in preparturient period during the study time.

With regard to the physical body condition the prevalence was significantly higher $(\mathrm{P}<0.05)$ in sheep with poor body conditions $(23.1 \%)$ than in those with medium $(14.8 \%)$ or good body conditions (8.8\%). The current finding is in agreement with studies reported by Selam et al. [32], Mihreteab and Aman [33] they reported higher prevalence rate in animals with poor body condition, but disagree with the finding of Weldesenebet and Mohamed [30] who reported higher prevalence rate in animals with good body condition. The variation in prevalence among the different body conditions might be associated with immune suppression in sheep with poor body conditions and concurrent infection by other parasites including gastrointestinal tract helminthes and/or malnutrition [33]. Poorly nourished sheep appear to be less competent in getting rid of lungworm infection and the infestation with a parasite by itself might results in progressive emaciation of the animals [34,35] (Table 2).

There was high significant difference between the prevalence rate of lung worm infection of sheep in the two management systems $(\mathrm{P}<0.05)$. It was found that $43 \%$ prevalence rate of lung worm infection was observed in animals under extensive management system, while very low prevalence rate, $3.6 \%$ was found in semi intensive management system. The current findings are in accordance with previous results of Yitagel et al. [18] in North Gondar Zone who reported prevalence rate of, $51.8 \%$ and $24.5 \%$ in extensive and semi intensive management system respectively. This could be due to the fact that sheep in extensive management system have a chance of grazing in the field contaminated with intermediate host for $P$. rufescens and $M$. capillaries or they possibly infested with larvae as well as easily obtained $D$. filarial from the herbage [36]. However, it contradicts with the result of Weldesenebet and Mohamed [30] who reported higher prevalence of lung worm infection in sheep under semi intensive management system (28.6\%) than in extensive management system $(26.0 \%)$.

The result of this study has shown that prevalence rate of lungworm infection in the study animals was significantly increase $(\mathrm{P}<0.05)$ with altitude, accordingly prevalence of $29 \%$ in high land and $17.6 \%$ in mid land areas was observed. This result is in agreement with the result reported by Alemu et al. [5] Mireteab and Aman [33] who found significant difference among the various agro-ecology $(\mathrm{P}<0.05)$ in their result. This might be due to the effect of altitude is attributable to climatic parameters. That is the survival and development of lungworm larvae is favored by low moisture content and high humidity [15].

The result of this study also showed that, $19.17 \%$ of those apparently healthy sheep and $27.46 \%$ of those showing clinical respiratory signs were infected with different lungworm species, with statistically significant variation $(\mathrm{P}<0.005)$ in prevalence rate. Similarly, with higher statistically significant variation $\left(\mathrm{x}^{2}=32.21, \mathrm{P}=0.00\right) D$. flaria was the dominant prevalent species in sheep with respiratory signs from the other lung worm species as clearly indicated in Table 2 . The result coincides with the observation of Alemu et al. [5], Desta et al. [28], Eyob and Matios [29] and Hasen et al. [37] in different parts of the country. This might probably due to the fact that during the end of prepatent phase of the parasite post patent parasitic bronchitis, which is responsible for clinical respiratory sign, developed and caused by immature lungworm in the air ways and cellular infiltration of the epithelium [24].

\section{Conclusion}

The result of present study indicated that lungworm is one of the major helminthosis of sheep in and around Wogera district, which is affecting the health and production performance of sheep. The prevalence of lung worm infection is significantly higher in young and animals under extensive management system but very low prevalence rate was observed in sheep kept under semi intensive management system. Dictocaulos flaria is the dominant lungworm species responsible for clinical manifestation of respiratory sign and higher prevalence rate of lungworm infection was observed in animal 
Citation: Yimer A, Desie A (2016) Epidemiological Studies on Ovine Lungworm Species in Northern Ethiopia. J Vet Sci Technol 7: 387. doi: 10.4172/2157-7579.1000388

Page 4 of 4

\begin{tabular}{|c|c|c|c|c|}
\hline Lungworm Species & $\begin{array}{l}\text { Apparently healthy animals }(n=240) \text { Prevalence } \\
(\%)\end{array}$ & $\begin{array}{c}\text { Animals with respiratory sign }(n=146) \\
\text { Prevalence }(\%)\end{array}$ & $x^{2}$ & P-value \\
\hline D. filaria & $32(8.3)$ & $41(10.6)$ & 32.21 & 0.00 \\
\hline M. capillaries & $23(6)$ & $32(8.3)$ & 8.74 & 0.00 \\
\hline P. rufescens & $5(1.3)$ & 4(1) & 0.87 & 0.32 \\
\hline Mixed infection & 14(3.6) & $29(7.5)$ & 18.05 & 0.01 \\
\hline Total & $74(19.17)$ & $106(27.46)$ & 60.5 & 0.00 \\
\hline
\end{tabular}

Table 2: Lungworm infection in relation to respiratory signs manifested.

with poor body condition and sheep sampled from relatively higher altitude areas. Therefore, emphasis should be given towards improving the overall health, nutritional conditions and management system of sheep in the study areas.

\section{References}

1. Central Statistical Authority (2006) Ethiopian agricultural sample survey. Vol II. Report on livestock and livestock characteristics. Statistical Bulletin 388. CSA, Addis Ababa, Ethiopia.

2. FAO (2004) Livestock sector brief: Ethiopia. Livestock information, sector analysis and policy branch (AGAL), FAO, Rome, Italy.

3. Taylor M, Coop R, Wall R (2007) Veterinary parasitology. 3rd edn. Black Well Publishing, IOWA, USA, pp: 94-97.

4. Ahmed EF, Markvichitr K, Tumwasorn S, Koonawootrittriron S, Choothesa A, et al. (2007) Prevalence of Fasciola spp infections of sheep in the Middle awash River Basin, Ethiopia. Southeast Asian J Trop Med Public Health 38: 51-52.

5. Alemu S, Leykun EG, Ayelet G, Zeleke A (2006) Study on small ruminant lungworms in northeastern Ethiopia. Vet Parasitol 142: 330-335.

6. FAO (2006) International scheme for the coordination of dairy development and International meat development scheme. Report of a mission to Ethiopia, May 27-June 28; Working paper 23; Rome, Italy.

7. Gelagay A, Leakemariam Y, Esayas G, Selam T, Kassahun A (2005) Study on the prevalence of lung worm infection in Gondar town. Ethiopian Vet J 9: 75-76.

8. Wogera Woreda Rural and Agricultural Office (WWRAO) (2007) Weather and Climate for casting Office.

9. ESGPIP (2007) Control of Internal Parasites in Sheep and Goats. Technical Bulletin 3. Ethiopia Sheep and Goat Productivity Improvement Program.

10. FAO (1993) Ethiopian Livestock sector development project. Preparation Report, FAO, Rome, Italy 1: 51.

11. Thrusfield M (2007) Veterinary epidemiology. 3rd edn. BlackWell Science Ltd. Cambridge, USA, pp: 225-228.

12. Moges N, Bogale B, Chanie M (2011) Dictyocaulus Filaria and Muellerius capillaris are Important Lungworm Parasites of Sheep in Wogera District, Northern Ethiopia. Int J Anim Vet Adv 3: 465-468.

13. Hendrix CM, Robinson E (2006) Diagnostic veterinary parasitological for veterinary technicians. 5th edn. Mosby Inc., St. Louis, Missouri, USA, p: 243.

14. Zajac AM, Conboy GA (2006) Veterinary Clinical Parasitology. 8th edn Australia Blackwell publishing, pp: 11-14.

15. Urquhart G, Armour J, Duncan A, Jennings F (1996) Veterinary Parasitology. 2nd edn. Blackwell Science, Scotland, pp: 39-58.

16. Mezgebu M (1995) A survey on ovine fascioliasis and lungworm infection in Addis Ababa and the surrounding highland areas. DVM Thesis, Faculty of Veterinary Medicine, Addis Ababa University, Debre-Zeit, Ethiopia.

17. Bogale B, Ebre A, Melaku A (2012) Ovine Lungworm Infection: Prevalence, Species Composition and Associated Risk Factors in Dessie Zuria District, Northeastern Ethiopia. Afr J Basic Appl Sci 4: 73-76.

18. Terefe Y, Tafess K, Fekadie G, Kebede N (2013) Prevalence of lungworm infection in small ruminants in North Gondar zone, Amhara National Regional State, Ethiopia. J Parasitol Vector Biol 5: 40-45.

19. Muluken Y (2009) Prevalence of ovine lungworms in and around Bahirdar. DVM thesis, college of Agriculture and Veterinary Medicine, School of Veterinary Medicine, Jimma University, Jimma, Ethiopia.

20. Tamire K, Mohamed A (2013) Prevalence of Ovine Lung Worms-Around Bahir Dar, East Africa, Ethiopia. Acta Parasitol Glob 4: 71-79.
21. Gebreyohannes M, Alemu T, Kebede E (2013) Prevalence of Ovine Lungworms in Mekedella Woreda, Ethiopia. J Anim Prod Adv 3: 208-214.

22. Tefera Y, Mekuria S (2016) Lungworm Infection in Ovine: Prevalence and Associated Risk Factors in Debre Birhan Town Ethiopia. J Vet Sci Technol 7: 303

23. Asaye M, Alemneh T (2015) Prevalence of Lungworm Infection of Small Ruminants in and Around Bahir Dar City, Amhara Regional State, Ethiopia. J Vet Sci Technol S12: 002.

24. Bradford $P$ (2002) Large Animal Internal Medicine. In: Veterinary Medicine: A text book of the disease of Cattle, Sheep, Pigs, Goats and Horse. 9th edn. Mosby. Inc., pp: 1452-1455.

25. Feseha G, Gebrenegus M (2004) Epidemiology of Dictyocaulus filaria in and around Debre Zeit, Modjo and a note in its prevalence at Alemaya 1976-1977. Report to the Ministry of Agriculture (MOA), Addis Ababa, Ethiopia, p: 16.

26. Teffera S, Melaku K, Asmamaw R (2006) The prevalence of ovine lungworm around Dessie and Kombolcha. DVM thesis, Faculty of Veterinary Medicine, Addis Ababa University Debreziet, p: 65.

27. Yohannes G (2006) Epidemiological study and an anthelmintic treatment trial of ovine dictyocaulosis in Debre Tabor town. M. S. thesis, Addis Ababa University, Faculty of Veterinary Medicine, Debre Zeit, Ethiopia.

28. Beyene D, Nigussie S, Ayana D, Abunna F (2013) The prevalence of lungworms in naturally infected sheep of Ambo District, Oromia, Ethiopia. Glob Vet 10: 93-98.

29. Eyob E, Matios L (2013) The prevalence and risk factors associated with ovine lungworm infestation in the Asella province, Central Ethiopia. J Parasitol Vector Biol 5: 116-121.

30. Weldesenebet $D$, Mohamed A (2012) Prevalence of small ruminant lung worm infection in Jimma town. Glob Vet 8: 153-159.

31. Addis M, Fromsa A, Ebuy $Y$ (2011) Study on the prevalence of lungworm infection in small ruminants in Gondar town, Ethiopia. J Anim Vet Adv 10: 16831687.

32. Tesfaye S, Hagos Y, Teklu A, Gugsa G, Gebrekidan B (2015) Ovine Lung Worm Infection and Associated Risk Factors in and Around Wukro, Eastern Tigray, Ethiopia. Eur J Biol Sci 7: 120-124.

33. Bekele M, Aman A (2011) Ovine Lungworms in Tiyo District, South Eas Ethiopia: Prevalence, Effect of Altitude and Major Host Related Risk Factors Glob Vet 7: 219-225.

34. Dar LM, Darzi MM, Mir MS, Kamil SA, Rashid A, et al. (2012) Prevalence and Pathology of Lung Worm Infection in Sheep in Kashmir Valley, India. J Anim Sci Adv 2: 678-685.

35. Radostits OM, Gay CC, Hinchcliff KW, Constable PD (2007) Veterinary Medicine: A textbook of the diseases of cattle, sheep, pigs, goats and horses, 10th edn. New York: Elsevier Saunders, pp: 1541-1564.

36. Radostits O, Gay C, Blood D, Hinchclift K (1994) Disease associated with helminthes parasites. In: Veterinary Medicine: A text book of the disease of Cattle, Sheep, Pigs, Goats and Horse. 9th edn. Harcourt Publishers, Ltd. London, pp: 1564-1569.

37. Hasen A, Takele S, Simenew K (2013) Ovine lungworm infestation rate on fecal larvae recovery basis. Acta Parasitol Globalis 4: 29-33. 